\title{
SITUAÇÕES DE VIOLÊNCIA NAS AULAS DE EDUCAÇÃO FÍSICA E A PRÁTICA PEDAGÓGICA DO PROFESSOR
}

\author{
Tiago Lepre Mello \\ Universidade Federal de São Carlos, São Carlos, São Paulo, Brasil \\ Douglas Aparecido de Campos \\ Universidade Federal de São Carlos, São Carlos, São Paulo, Brasil
}

\begin{abstract}
Resumo
O presente estudo teve como objetivo identificar situações de violência nas aulas de Educação Física, bem como os possíveis motivos para tais ocorrências, e discutir aspectos da prática pedagógica do professor que se relacionam com o surgimento dessas situações. A pesquisa foi realizada em duas escolas, com a participação de dois professores de Educação Física e duas turmas de alunos do $5^{\circ}$ ano do Ensino Fundamental. A metodologia qualitativa subsidiou o estudo e o diário de campo foi utilizado como instrumento metodológico. Os resultados mostram que práticas licenciosas e autoritárias por parte dos professores acabam por possibilitar espaços de relacionamentos sociais suscetíveis ao surgimento de nove situações conflitivas em que os alunos apresentaram comportamentos violentos.
\end{abstract}

Palavras-chave: Violência. Educação Física. Professor. Prática Pedagógica.

\section{SITUATIONS OF VIOLENCE IN PHYSICAL EDUCATION CLASSES AND TEACHER'S PEDAGOGICAL PRACTICE}

\begin{abstract}
The present study aimed to identify situations of violence in Physical Education classes, as well as the possible reasons for such occurrences, and to discuss aspects of the teacher's pedagogical practice that relate to the emergence of these situations. The research was carried out in two schools, with the participation of two teachers of Physical Education and two classes of students of the 5th year of Elementary School. The qualitative methodology subsidized the study. The field diary was used as a methodological tool. The results show that the licentious and authoritarian practices of teachers allowed spaces of social relationships susceptible to the emergence of nine conflicting situations in which the students presented violent behavior.
\end{abstract}

Keywords: Violence. Physical Education. Teacher. Pedagogical Practice.

\section{SITUACIONES DE VIOLENCIA EN LAS CLASES DE EDUCACIÓN FÍSICA Y LA PRÁCTICA PEDAGÓGICA DEL PROFESOR}

\section{Resumen}

El presente estudio tuvo como objetivo identificar situaciones de violencia en las clases de Educación Física, así como los posibles motivos para tales ocurrencias, y discutir aspectos de la práctica pedagógica del profesor que se relacionan con el surgimiento de esas situaciones. La investigación se realizó en dos escuelas, con la participación de dos profesores de Educación Física y dos clases de alumnos del $5^{\circ}$ año de la Enseñanza Fundamental. La metodología 
cualitativa subsidió el estudio. El diario de campo se utilizó como instrumento metodológico. Los resultados muestran que las prácticas Licenciosa y Autoritaria de los profesores posibilitar espacios de relaciones sociales susceptibles al surgimiento de nueve situaciones conflictivas en que los alumnos presentaron comportamientos violentos.

Palabras clave: Violencia. Educación Física. Professor. Prática Pedagógica.

\section{Introdução}

Segundo Viana (2002, p. 112), a violência é uma forma específica de relação social, "caracterizada pela imposição de algo realizada por um indivíduo/grupo social a outro indivíduo/grupo social, contra sua vontade ou natureza". Contudo, a relação impositiva nem sempre é acompanhada de intencionalidade. A intenção está presente nos casos mais explícitos (físicos, verbais, psicológicos), pois quando a imposição é implícita no âmbito ideológico, simbólico e cultural, tanto os agentes quanto as vítimas da violência não a percebem como tal.

No âmbito escolar a violência é entendida sob duas perspectivas. Na primeira, a escola ocupa o posto de vítima, espaço físico onde os atos violentos acontecem. Charlot (2002) destaca a violência na escola, produzida dentro dela, mas sem relação com a natureza das atividades escolares, e a violência à escola, produzida contra ela, caracterizada por direcionar-se diretamente ao ambiente escolar e a seus componentes.

Na segunda, a escola ocupa o posto de causadora da violência. Nesta perspectiva, Charlot (2002) denomina de violência da escola a violência simbólica e institucional produzida pela própria escola, como a imposição da cultura escolar e sua incompatibilidade com as necessidades e interesses presentes na pluralidade cultural dos alunos, o autoritarismo docente e excessos em sanções normalizadoras. Para Abramovay (2006, p. 77), este tipo de violência também pode se manifestar "por meio do modo como a escola se organiza, funciona e trata os alunos (modo de composição das classes, atribuição de notas, tratamento desdenhoso ou desrespeitoso por parte dos adultos, entre outras coisas)". A distinção entre as duas perspectivas sobre a violência no âmbito escolar torna-se importante para conscientizar o professor e a instituição sobre sua possível influência na dinâmica de prevenção e desenvolvimento da violência escolar.

Como componente curricular da Educação Básica, a Educação Física apresenta um potencial socializador e educativo que pode promover benefícios na formação biopsicossocial dos alunos em relação ao enfretamento de comportamentos e atitudes violentas. Suas atividades proporcionam experiências afetivas, emocionais, cognitivas, motoras e sociais que podem contribuir com o processo saudável de relacionamento interpessoal. Deste modo, Correia et al. (2010, p. 153) dizem que a Educação Física assume:

[...] um papel social e transformador, de uma prática educativa comprometida com a formação de atitudes e valores para que, desta forma, o educando possa perceber a importância das relações interpessoais para a transformação de sua condição enquanto sujeito de relações afetivas, cognitivas e, sobretudo, morais, para poder viver sem agredir ou prejudicar o outro. Assim, estará contribuindo para a formação de um sujeito crítico e emancipado, possibilitando um novo olhar no modo de ser, ver e intervir no mundo.

Ainda que a Educação Física possua um grande potencial pedagógico capaz de contribuir para a melhoria do relacionamento interpessoal dos alunos, ela por si só não soluciona o problema da violência, que se insere como parte integrante das relações que perpassam o ambiente escolar. Para que seus benefícios sejam promovidos, a prática pedagógica do professor 
precisa proporcionar uma visão mais próxima das relações humanas. Por meio do enfrentamento cotidiano da violência escolar, o professor de Educação Física pode desenvolver uma educação de valores e privilegiar a formação de comportamentos, hábitos e condutas saudáveis de relacionamento e convivência social dos alunos.

A ocorrência constante desse fenômeno da violência na área da Educação Física escolar mostra-se preocupante. Os estudos de Bróglio (2003), Peres (2005), Ferreira (2010) e Castro et al. (2013) revelam diversos aspectos sobre a dinâmica da violência nas aulas de Educação Física e apontam fatores relacionados à prática pedagógica do professor que podem facilitar a manifestação de situações de violência, como a pouca variedade entre as atividades práticas, a ausência do diálogo entre professor e aluno, aulas desestimulantes e sem metodologia adequada, a omissão do professor em situações conflituosas, a ausência de planejamento, a predominância do conteúdo "esporte" (praticado sob códigos de rendimento) e a existência da violência simbólica do professor, representada por condutas agressivas.

Embora as ações violentas possam ocorrer em decorrência da qualidade do relacionamento social dos alunos ou durante suas participações nas atividades pedagógicas; antes, elas ocorrem sob o trabalho pedagógico do professor. Desse modo, tem-se a hipótese de que a manifestação do comportamento violento dos alunos se deve a aberturas para espaços de situações conflitivas, que podem ser desencadeadas em meio à prática pedagógica do professor de Educação Física.

Com o objetivo de identificar situações que são motivo de violência nas aulas de Educação Física e discutir possíveis aspectos da prática pedagógica do professor, que se relacionam com o surgimento dessas situações, este estudo focou na prática pedagógica do professor para responder a seguinte questão: quais situações geram violência nas aulas de Educação Física e como o trabalho docente pode se relacionar com essas situações?

\section{Procedimentos metodológicos}

A abordagem qualitativa foi utilizada para compreender a dinâmica da violência que ocorre nas relações sociais durante as aulas de Educação Física. Optou-se pela pesquisa do tipo descritiva-exploratória, que, conforme Gil (2002), descreve as características e proporciona maior familiaridade com o objeto estudado.

A pesquisa foi realizada em duas escolas públicas (A e B), localizadas em bairros periféricos, que atuam exclusivamente com os anos iniciais do Ensino Fundamental. Participaram dois professores de Educação Física e duas turmas do $5^{\circ}$ ano. Os professores receberam nomes fictícios (Antônio e Bernardo).

O professor Antônio atua na escola "A" e há sete anos é formado em Educação Física, sendo que não possui curso de formação continuada. O professor Bernardo atua na escola "B" e há dez anos é formado em Educação Física. Ele possui formação continuada em dois cursos de especialização (Pedagogia do Esporte e Educação Física escolar) e atualmente é aluno de mestrado em Educação Física.

No período de seis meses, foram observadas trinta e sete aulas de Educação Física nas duas escolas participantes (vinte na escola "A" e dezessete na escola "B"). Segundo Chizzotti (2000), a observação objetiva a descrição de todos os componentes da situação, como os sujeitos e seus aspectos particulares, o local e as circunstâncias. Devido à possibilidade de manter contato direto com o objeto de estudo em seu ambiente natural, foram observados os trabalhos pedagógicos dos professores, as atividades propostas, o relacionamento interpessoal professor-aluno e aluno-aluno, os comportamentos e situações violentas, enfim, toda dinâmica de relacionamento social.

Para Triviños (2013, p. 154), "todo o processo de coleta e análise de informações" deve ser feito em anotações de campo. Assim, o diário de campo foi adotado como instrumento 
metodológico e os dados obtidos no campo de pesquisa foram coletados em um caderno brochura. O pesquisador ocupou o posto de espectador, sem interferir no desenvolvimento das aulas, posicionando-se em um local estratégico que possibilitou a escuta e a visualização de situações conflitivas, os protagonistas, as causas e os comportamentos violentos. Os dados e as reflexões sobre o contexto do fenômeno "violência" foram registrados no momento dos acontecimentos para preservar os detalhes e a fidelidade das análises. O projeto de pesquisa foi submetido ao Comitê de Ética em Pesquisa (CEP) e obteve o parecer de aprovação $\mathrm{n}^{\circ}$ 1.015.759.

\section{Resultados e discussão}

No decorrer das observações das aulas de Educação Física e do trabalho pedagógico dos professores, foram verificados momentos em que o relacionamento social dos alunos ficou mais suscetível à manifestação de violência. No processo de análise dos dados, esses momentos representam nove situações motivo de violência e estão associados a dois tipos de práticas pedagógicas desenvolvidas pelos professores: prática licenciosa e prática autoritária.

\section{Prática licenciosa}

O termo prática licenciosa refere-se aos momentos de trabalho pedagógico desestruturado, desprovido de orientação teórica, didática e metodológica, em que os professores não apresentam compromisso com a profissão, não estabelecem limites para as ações dos alunos, não possuem o controle das atividades e permanecem alheios aos seus acontecimentos e desdobramentos. As práticas licenciosas ocorreram em momentos distintos das aulas, porém foram frequentemente observadas na parte final, momento em que os professores deixavam os alunos à vontade para fazerem o que desejassem.

Os alunos possuíram liberdade para escolher as atividades e a forma como desejavam realizá-las. Desamparados de mediação pedagógica, costumeiramente eles fundamentaram os códigos do esporte de rendimento em suas participações e revelaram seus comportamentos violentos nas relações sociais estabelecidas. Os jogos e os esportes coletivos com bola foram as atividades que prevaleceram entre os alunos e se destacaram em relação à frequente ocorrência de situações de violência, que se mostraram intensas nos momentos de competitividade elevada.

Para Ferreira (2010, p. 114), "ao léu, os alunos sem orientação de um professor acabam criando situações de conflito que frequentemente acabam em agressões (...)". De fato, a omissão dos professores na prática licenciosa e a prevalente adoção dos códigos do esporte de rendimento nas práticas da Educação Física facilitaram o surgimento de espaços para seis situações em que os alunos manifestaram comportamentos violentos, quais sejam:

Contato corporal em atividades de grupo: refere-se ao contato corporal entre os alunos, ou entre a bola e o corpo do aluno, realizado de modo ríspido ou com a utilização de força desproporcional nas atividades práticas de grupos.

Nos jogos e esportes com bola, o contato corporal entendido como situação de violência ocorreu entre os alunos que disputavam a posse da bola por meio de perigosos choques corporais, jogadas faltosas e empurrões. Os embates corporais ríspidos normalmente não foram aceitos pelos alunos que se sentiram vítimas de um ataque intencional, e configuraram espaços que propiciaram o surgimento de ameaças, intimidações, xingamentos e brigas. Como exemplo, no basquetebol, um aluno utilizou movimentos bruscos com o corpo para deslocar o adversário. A vítima imediatamente revidou com socos e chutes. No futsal, o aluno realizou um "carrinho" para bloquear o chute do adversário, porém o carrinho atingiu o corpo do cole- 
ga, derrubando-o no chão. A vítima se levantou e proferiu xingamentos, intimidou e ameaçou de agressão o colega que o atingiu.

Erro de jogo: foi a situação motivo de violência que predominou durante as aulas e refere-se aos erros técnicos realizados pelos alunos nos jogos ou esportes abordados de forma competitiva. Errar o alvo, perder a posse de bola e sofrer pontos foram os erros que mais alavancaram desentendimentos, seguidos de ataques físicos, verbais e psicológicos entre os alunos. No futsal, foi observado um goleiro que falhou sucessivamente, resultando em diversos gols sofridos. Como consequência dos erros, o goleiro foi excluído do jogo pelos demais alunos. A vítima ainda recebeu gozações e revidou com ameaças de agressão. Em outra situação, o aluno errou a finalização ao gol e recebeu vários xingamentos e ameaças dos outros alunos da equipe. $\mathrm{O}$ mesmo aconteceu com alunos que erraram passes ou tentaram sem êxito driblar os adversários.

Resultado de jogo: refere-se a situações de supervalorização da vitória, descaso e não aceitação da derrota, que ocorreram tanto entre alunos de equipes adversárias quanto entre alunos da mesma equipe.

Em relação aos alunos de equipes adversárias, as situações de violência se repetiram em diferentes atividades esportivas, quando os vencedores manifestaram atitudes de desrespeito e gozação com o intuito de provocar, humilhar e menosprezar os derrotados. Os derrotados reagiam a tais provocações com intimidações, ameaças, xingamentos e empurrões. Entre os alunos da mesma equipe, a não aceitação da derrota pôde ser verificada nas discussões para determinar os culpados pela derrota; como no futsal, em que o aluno culpou o colega pela derrota da equipe devido aos erros por ele cometidos no jogo. Este não concordou e iniciou uma discussão permeada de xingamentos e ameaças.

Regra de jogo: representa as divergências sobre as regras de jogos e esportes que suscitaram situações de conflito e violência entre alunos. Identificou-se que as situações de violência foram mais frequentes quando ocasionadas em decorrência de violações de regras referentes à posse de bola, à marcação do ponto e à eliminação de participantes da equipe.

Divergências sobre regras que determinavam a posse da bola foram observadas em faltas e laterais do futsal, basquetebol e handebol. Na queimada, o aluno do "cemitério" pegou a bola dentro do campo dos alunos que não estavam queimados. Tal ação gerou discussão e o aluno que estava com a posse da bola atirou-a com força no rosto de uma colega. Divergências sobre regras que determinavam a marcação do ponto foram observadas no futsal e no voleibol. No futsal, um aluno fez o gol e os alunos da equipe adversária afirmaram que havia ocorrido uma falta na jogada anterior. No voleibol, os alunos questionaram a marcação do ponto, alegando que a bola caiu fora da quadra. Em ambas as situações, a marcação do gol e do ponto foram negadas, porém delas emergiram conflitos permeados de violência verbal. Divergências sobre regras que determinavam a eliminação de um participante foram observadas na queimada, em que um aluno alegou não ter sido atingido pela bola e os alunos da equipe adversária alegaram o contrário. $\mathrm{O}$ aluno não aceitou tal imposição, atirou a bola longe e xingou os colegas, que revidaram da mesma forma.

Exclusão: refere-se a situações silenciosas em que os alunos não participaram das atividades. As situações de exclusão aconteceram de duas maneiras: direta e indireta.

A exclusão direta remete à privação do direito do aluno de participar das atividades desenvolvidas nas aulas, como os que não participaram por não serem selecionados para compor as equipes devido à pouca habilidade técnica, pouca afinidade com o grupo ou pela ausência de vagas. Tais situações ocorreram nos momentos de formação das equipes, que costumeiramente foram gerenciadas pelos alunos. Também houve casos de exclusão direta da atividade como forma de punição à vítima, devido a erros por ela cometidos (como o caso do goleiro citado). 
A exclusão indireta remete aos alunos que, mesmo incluídos nas atividades, não participaram delas efetivamente por serem ignorados pelos demais, como verificado no futsal, em que o aluno não recebeu a bola durante toda a partida. No basquetebol, o aluno participou, sujeitando-se às imposições do grupo para desempenhar função de menor prestígio entre eles, como a posição de defensor.

As exclusões, além de serem formas implícitas de violência, também foram motivos desencadeadores de violência verbal e física, pelo fato de as vítimas apresentarem sentimentos de insatisfação e indignação com a situação a que foram submetidas, como observado no aluno que não foi escolhido para participar do futsal e chutou os cones que demarcavam as balizas do gol. Imediatamente, outro aluno chutou a bola na vítima excluída e depois a empurrou, intimando-a para colocar os cones no lugar.

Ociosidade: refere-se aos momentos de ócio durante as aulas, verificado nos alunos excluídos e nos descomprometidos com a participação nas atividades. A ociosidade dos alunos propiciou o surgimento dos atos corriqueiros de mau gosto (brincadeiras/provocações pertencentes à cultura lúdica dos alunos e que ocorrem paralelamente à atividade do professor) com a intenção de zombar e humilhar os colegas. Alguns destes atos verificados foram: abaixar a calça, dar tapas na cabeça, aplicação de golpes para derrubar o colega, tocar em partes íntimas, pegar ou esconder o material, puxar o cabelo, fazer piadas e gozações, entre outras ações.

A maior incidência da prática desses atos aconteceu em momentos sem a supervisão do professor. Nessas ocasiões, as provocações lúdicas tenderam a extrapolar os limites da convivência saudável e terminaram de forma violenta, como no caso do aluno que teve sua calça abaixada durante a atividade de arremessos do basquetebol, e reagiu com chutes e socos. Também foi verificado que esses atos ocorreram simultaneamente à participação dos alunos nas atividades, como na queimada, em que alguns alunos estavam ociosos no "cemitério" praticando atos de gozação contra uma aluna. A vítima revidou com xingamentos e deixou o jogo. A ociosidade dos alunos durante as atividades deve-se principalmente à exclusão indireta, ocasionada pela ausência de oportunidade para receber a bola, por exemplo. Também foram observados alunos que não participaram das atividades por opção ou porque foram excluídos. Em ambos os casos, os alunos ociosos também realizaram atos corriqueiros de mau gosto que terminaram em violência.

\section{Prática autoritária}

Refere-se ao autoritarismo do professor, implícito nos modos de agir perante os alunos e na forma de conduzir práticas e intervenções pedagógicas. Na prática autoritária, a conduta do professor envolve a adoção de posturas hostis, agressivas, autoritárias e punitivas, geralmente utilizadas para manter o domínio da turma, recuperar o controle dos alunos e punir excessos e divergências conflituosas. Conforme Freire (2012, p. 118), o autoritarismo docente:

[...] não se manifesta apenas no uso abusivo, repressivo, de sua autoridade, que restringe arbitrariamente os movimentos dos educandos. Se manifesta igualmente num sem-número de momentos e de oportunidades. Na vigilância doentia exercida sobre os educandos, na falta de respeito à sua criatividade, à sua identidade cultural. $\mathrm{Na}$ falta de acatamento à maneira de estar sendo dos alunos das classes populares, na maneira como os adverte ou os censura.

Na Prática Autoritária, destacaram-se três ações específicas do trabalho docente que se transformaram em situação motivo de violência, isto é:

Hostilidade no relacionamento professor-aluno: refere-se à utilização de palavras ríspidas, agressivas e com alta entonação de voz, em que o professor realizou intervenções 
pedagógicas ou "chamou a atenção" dos alunos de modo desrespeitoso, como observado no aluno que foi repreendido aos gritos pelo professor Bernardo porque estava chutando a bola na parede, sem prestar atenção na explicação.

O desrespeito, além de implícito no diálogo agressivo e hostil, também foi visto em situações em que o professor Antônio ironizou alguns alunos por suas dificuldades técnicas, limitações físicas e corporais, como na corrida com obstáculos, em que o professor apelidou o aluno de "tartaruga", devido à sua pouca velocidade, baixa estatura e elevado peso corporal. Os demais alunos zombaram dele por isso. A vítima revidou com xingamentos e deixou a atividade. Ao ser convidado a retornar, a vítima agrediu o professor verbalmente. O tratamento desrespeitoso e irônico expôs os alunos ao ridículo e estimulou gozações e humilhações que causaram desistências e revoltas violentas contra o professor ou contra os colegas.

Prática punitiva: foi a principal forma de intervenção dos professores nas situações de conflito e violência. A punição mais utilizada foi a prática da exclusão, que variou de acordo com as situações ocorridas. Conforme Castro et al. (2013), além de não resolver o problema, a prática da exclusão também implica duas dificuldades: a inexistência de postura formativa nos professores e a impossibilidade de professores e alunos refletirem sobre o ocorrido.

Verificaram-se a exclusão do aluno da atividade, a exclusão acompanhada do encaminhamento à sala de aula, a exclusão acompanhada do encaminhamento à diretoria, a interrupção da aula e o encaminhamento de toda a turma à sala. A punição mais severa ocorreu no futsal, no qual houve uma disputa ríspida de bola e um aluno proferiu xingamentos ao outro. A vítima revidou, e a violência verbal se transformou em violência física. O professor Antônio interviu de forma agressiva, pedindo aos gritos para que os alunos parassem de brigar. Devido à postura do professor, um dos envolvidos o violentou verbalmente. De imediato, o professor interrompeu a aula e pôs-se a voltar com todos os alunos para a sala, encaminhando os envolvidos na briga à diretoria. Os alunos que brigaram foram suspensos por um mês das aulas de Educação Física pela diretora.

Embora a prática punitiva possa ter sido adotada na intenção de conscientizar os alunos sobre suas ações, ao trocar o diálogo pela punição e pelas broncas que os ridicularizam, verificou-se que tais ações apenas despertam sentimentos de insatisfação e que, por vezes, incitam revoltas. Nesse sentido, Freire (2014) alerta que infelizmente muitos professores de boa vontade comprometidos com uma educação libertadora ainda não se percebem como executores de uma educação tradicional, por sofrerem a influência contida nesse modelo de educação e fazerem uso incorreto de um instrumento punitivo e alienador em busca do desenvolvimento da consciência crítica do aluno.

Exercício do autoritarismo docente: representa a prática ameaçadora, a imposição de regras que restringem a participação dos alunos nas aulas e a imposição arbitrária da vontade do professor, expressa em suas decisões diante de situações conflituosas.

Conforme Fante (2005), o professor que age de modo autoritário e intimidador, na busca de poder e controle da turma, também pode se transformar em agressor. Os professores recorreram a práticas ameaçadoras para recuperar a ordem e manter o controle da turma durante as atividades e na resolução dos conflitos. Também foi observada a prática ameaçadora associada à imposição de atividades, em que os alunos foram obrigados a participar sob a ameaça de punições, como o aluno que não queria jogar o vôlei adaptado, mas foi obrigado pelo professor Bernardo mediante ameaça de ser enviado à sala. A ameaça do professor fomentou gozações contra o aluno exposto a tal situação, que revidou com violência verbal e chutou a bola contra um colega.

$\mathrm{O}$ autoritarismo docente também esteve presente no estabelecimento de regras rígidas cujos sentidos expressaram a normatização da aula por meio do controle excessivo sobre os alunos. A regra imposta de modo autoritário, como instrumento elaborado apenas para limitar a experiência corporal e social dos alunos ou para puni-los, foi considerada violência discipli- 
nar, cuja intenção é garantir a ordem e a disciplina por meio da vigilância, do controle e de sanções normalizadoras e punitivas (VIANA, 2002).

É sabida a importância da regra no convívio social escolar e na estruturação do trabalho pedagógico do professor, mas para que possa atingir sua finalidade, a regra precisa integrar ações e estratégias educativas e reflexivas, ter significados para o aluno e estar em consonância com sua realidade econômica e social, respeitando também a diversidade, as necessidades, a liberdade, os direitos e características da faixa etária. No entanto, algumas regras observadas proibiram os alunos de participarem da aula usando boné, blusa de frio com capuz, touca e chinelo. Transgressões a tais regras implicaram em broncas hostis e foram passíveis de práticas punitivas. Os alunos que foram à escola de chinelo e os que se recusaram a retirar a blusa automaticamente foram impedidos de participar da aula. Um dos alunos que não retirou a blusa foi proibido de jogar futsal, e reagiu com xingamentos e gestos obscenos contra o professor, que o encaminhou para a direção da escola.

A imposição arbitrária da vontade do professor remete-se à força utilizada em suas intervenções e decisões. Tais ações geralmente foram desprovidas de diálogo, não consideraram as situações conflitivas, abrangeram punições, abuso de autoridade e intervenções que geraram sentimento de injustiça nos alunos. Conforme Castro et al. (2013), a ausência do diálogo na resolução dos conflitos potencializa as manifestações de violência entre os alunos e entre o professor e o aluno. Foi observado no jogo de queimada muitas dúvidas sobre regras e, em todas elas, o professor atuou como árbitro, resolvendo os conflitos. Visivelmente irritado com a quantidade de conflitos que ocorria, o professor decidiu terminar o jogo e concedeu a vitória para uma das equipes. Tal decisão gerou revolta nos alunos perdedores, que questionaram a decisão. O professor a defendeu de maneira hostil, ridicularizando os alunos perdedores e os colocando de castigo por dez minutos, sentados na arquibancada. Duas meninas que estavam ociosas zombaram dos alunos excluídos, que revidaram com xingamentos.

Na perspectiva de Charlot (2002) e Abramovay (2006), ambas as práticas discutidas neste texto podem ser consideradas como violência institucional e simbólica, pois, na prática licenciosa, o professor negligencia sua função social e nega aos alunos o direito à educação de qualidade, o acesso ao conhecimento e a participação no universo da cultura corporal de movimento; e, na prática autoritária, o professor se relaciona com os alunos de modo vertical, empregando força e coerção por meio de autoritarismo, hostilidade, desrespeito e punições. Para Freire (2011) as práticas licenciosa e autoritária são rupturas do equilíbrio entre liberdade e autoridade, e remetem-se à postura docente que contradiz o trabalho pedagógico coerente e dialógico.

Apesar de os contextos sociais das escolas apresentarem semelhanças, os alunos da escola "A" demonstraram-se mais propensos a expressarem comportamentos violentos, fato que pode representar a influência da família e do meio social na formação desses alunos, mas que também representa a existência de espaços de relacionamentos que estimulam a manifestação desses comportamentos.

A formação mais aprofundada do professor Bernardo foi considerada um indicador de qualidade do seu trabalho. Aparentemente, esse fator conseguiu diminuir a exposição dos alunos ao risco e à manifestação de violência nas aulas de Educação Física da escola "B". Mesmo sem receber formação específica sobre a violência no contexto escolar, o professor mais capacitado dispôs de conhecimentos, estratégias e métodos de ensino capazes de prevenir e reduzir a ocorrência da violência, ao proporcionar atividades repletas de estímulos para aprendizagens e interações sadias entre os alunos, que não encontraram espaços ou situações para manifestarem comportamentos violentos.

É importante ressaltar que quando o trabalho pedagógico foi coerente com a proposta educacional e socializadora da Educação Física, em que a interação professor-aluno foi permeada de respeito e diálogo, e as atividades propostas foram significativas e conectadas à 
realidade e aos interesse dos alunos, não houve manifestação de violência nas duas escolas analisadas, e a tendência dos alunos da escola "A" de se expressarem de modo mais violento foi minimizada. Isso pôde ser observado na realização de atividades regidas sob os princípios que compõem o modelo do esporte escolar, no desenvolvimento do conteúdo atitudinal incorporado em meio às atividades práticas, nas atividades cooperativas, e nas adaptações de regras, em que os professores redirecionaram os objetivos das atividades e desviaram o foco da competição.

\section{Considerações finais}

Considerou-se, neste estudo, que a alienação do professor em relação aos acontecimentos da aula, o não comprometimento com a função docente, a ausência de diálogo e o desrespeito na relação professor-aluno, presentes nas práticas licenciosa e autoritária, possibilitaram espaços de relacionamentos sociais suscetíveis ao surgimento de nove situações conflitivas, em que os alunos apresentaram comportamentos violentos. No entanto, é preciso destacar que ambas as práticas não possuem relação direta com os comportamentos violentos dos alunos, sendo apenas facilitadoras de espaços que podem propiciar situações que fazem emergir os comportamentos violentos que integram a formação pessoal e social dos alunos.

A ausência de conhecimentos sobre a violência escolar tanto pode limitar o trabalho pedagógico e dificultar a elaboração de atividades preventivas e socializadoras com menor risco à ocorrência de situações de violência, como observado na prática licenciosa; quanto pode prejudicar a intervenção pedagógica reflexiva, na qual o professor dispensa a prática dialógica e opta por ações coercitivas e punitivas na intenção de conscientizar os alunos sobre suas condutas, como observado na prática autoritária.

Garoni et al. (2012) dizem que a dificuldade, a ausência de conhecimento e a incapacidade de mediar situações conflitivas e violentas possuem relação direta com as bases formativas do professor. A observação constante do trabalho pedagógico desestruturado e da troca do diálogo por práticas hostis e punitivas evidenciam essa perspectiva e nos direciona a rever a formação do professor para enfoques que o auxiliem em intervenções dialógicas e reflexivas nos diversos problemas que envolvem o cotidiano da profissão, como aqueles implícitos na dinâmica do relacionamento social que impedem o desenvolvimento de conhecimentos e habilidades necessárias para o exercício global da função educativa.

Nesse contexto, para conduzir um trabalho docente capaz de transformar o aluno, o professor não pode ser autoritário e nem licencioso e existe a necessidade de se construir limites, por meio de uma postura de autoridade democrática. Para isso, as práticas pedagógicas devem ter uma relação ética permeada de respeito, e o professor de Educação Física precisa atentar-se em promover ambientes saudáveis de interação, que privilegiem a formação de valores morais, afetivos e sociais nos alunos, e o sentimento de responsabilidade na construção de uma sociedade mais justa e menos violenta.

\section{Referências}

ABRAMOVAY, M. Cotidiano das escolas: entre violências. Brasília: UNESCO, 2006.

BRÓGLIO, L. P. Agressividade nas aulas de educação física escolar: encontros ou desencontros? 2003. 123 f. Dissertação (Mestrado em Educação Física)-Faculdade de Ciências da Saúde, Universidade Metodista de Piracicaba, Piracicaba, 2003. Disponível em: <http://www.nuteses.temp.ufu.br/tde_busca/arquivo.php?codArquivo=4872\&acordo=>. Acesso em: 16 jan. 2016. 
CASTRO, J. T. et al. Violência em aulas de educação física: corporalidade, docência e formação. Rev. Iberoamericana de Educación. n. 62: p. 19-37, 2013. Disponível em: <http://www.rieoei.org/rie62a01.pdf>. Acesso em: 16 jan. 2016.

CHARLOT, B. A violência na escola: como os sociólogos franceses abordam essa questão. Sociologias, Porto Alegre, ano 4, n. 8, p. 432-443, jul./dez. 2002.

CHIZZOTTI, A. Pesquisa em ciências humanas e sociais. 4. ed. São Paulo: Editora Cortez, 2000.

CORREIA, M. S. et al. O papel da educação física escolar diante do fenômeno da violência na escola. Revista Interação, São Paulo, ano 16, n. 61, p. 149-154, abr./jun. 2010.

FANTE, C. Fenômeno Bullying: como prevenir a violência nas escolas e educar para a paz. 7. ed. Campinas: Editora Verus, 2005.

FERREIRA, C. S. Práticas de violência no espaço escolar do Distrito Federal: uma interpretação do fenômeno nas aulas de Educação Física. 2010. 140f. Dissertação (Mestrado em Educação Física)-Faculdade de Educação Física, Universidade de Brasília, Brasília, 2010.

FREIRE, P. Pedagogia da Autonomia: saberes necessários à prática educativa. 43. ed. São Paulo: Editora Paz e Terra, 2011.

FREIRE, P. À sombra desta mangueira. 10. ed. Rio de Janeiro: Editora Civilização Brasileira, 2012.

FREIRE, P. Pedagogia do oprimido. 56. ed. Rio de Janeiro: Editora Paz e Terra, 2014.

GARONI, P. C. et al. Violência escolar e educação física. Revista Digital EFDeportes, Buenos Aires, ano 17, n. 167, abr. 2012. Disponível em: <http://www.efdeportes.com/efd167/violencia-escolar-e-educacao-fisica.htm>. Acesso em: 16 jan. 2016.

GIL, A.C. Como elaborar projetos de Pesquisa. 4. ed. São Paulo: Editora Atlas, 2002.

PERES, L. S. A prática pedagógica do professor de Educação Física: atitudes de violência no contexto escolar. 2005. 326 f. Tese (Doutorado em Educação)-Pontifícia Universidade Católica de São Paulo, São Paulo, 2005.

TRIVIÑOS, A. N. S. Introdução à pesquisa em ciências sociais: a pesquisa qualitativa em educação - o positivismo, a fenomenologia, o marxismo. São Paulo: Editora Atlas, 2013.

VIANA, N. Violência e escola. In: VIANA, N.; VIEIRA, R. G. (Org.). Educação, cultura e sociedade: abordagens críticas da escola. Goiânia: Edições Germinal, 2002. 
Endereço para correspondência:

tiagaomello@gmail.com

Tiago Lepre Mello

Universidade Federal de São Carlos, Centro de Educação e Ciências Humanas.

Rod. Washington Luiz Km 235

13560-000 - Sao Carlos, SP - Brasil 